\title{
OS CIDADÃOS MUNDIAIS ENTRE A LIBERDADE E A SEGURANÇA*
}

\author{
KLAUS GÜNTHER \\ TRADUÇÃO: PEDRO MAIA
}

\section{RESUMO}

O 11 de setembro acelerou o desenvolvimento de uma arquitetura transnacional de segurança que intervém profundamente nas liberdades civis individuais, tanto nos direitos básicos dos cidadãos dos Estados como nos direitos humanos dos cidadãos mundiais. $\mathrm{O}$ artigo delineia essa arquitetura, mostra como ela dissolve as categorias jurídicas tradicionais que preservam a liberdade e discute por que hoje se aceita amplamente a prioridade da segurança sobre a liberdade.

PALAVRAS-CHAVE: arquitetura transnacional de segurança; liberdades civis; direitos humanos; terrorismo.

\section{SUMMARY}

The $9 / 11$ attacks triggered the development of a transnational security architecture that interferes profoundly in individual civil liberties, in the basic rights of State citizens as much as in human rights of the world citizens. The article draws this architecture, shows how it dissolves traditional juridical categories that preserve freedom and discusses why today it's accepted the priority of security over freedom.

KEYWORDS: transnational security architecture; civil liberties; human rights; terrorism.

[*] Tradução do texto "World citizens between freedom and security". Constellations, vol. $12, \mathrm{n}^{\circ} 3,2005$. Revisão técnica de José Rodrigo Rodriguez.
Na esteira de novas liberdades, a globalização trouxe novas inseguranças. $\mathrm{O}$ alcance da liberdade econômica está se tornando maior; as tecnologias modernas expandem ainda mais as possibilidades da comunicação e, com elas, outro aspecto da liberdade. Porém, o maior ganho em liberdade pode ser observado no direito internacional. Na qualidade de sujeito dos direitos humanos, o indivíduo torna-se sujeito do direito internacional, e, junto com os Estados soberanos, o único portador de subjetividade jurídica internacional. Isso está expresso com a maior clareza no Estatuto de Roma, que criou o Tribunal Penal Internacional. A comunidade internacional coloca o indivíduo sob sua proteção contra Estados soberanos que cometem as violações mais graves aos direitos humanos. Com isso, os cidadãos nacionais, em sua maioria, passam a ser, ao mesmo tempo, cidadãos mundiais. O diagnóstico otimista de Kant parece ter-se tornado finalmente realidade: 
Os povos da terra entraram assim, em graus variados, numa comunidade universal, e ela se desenvolveu a tal ponto que uma violação de direitos em uma parte do mundo ésentida em todos os lugares. A idéia de um direito do cidadão cosmopolita não é, portanto, fantástica ou exagerada; é um complemento necessário ao código não-escrito do direito político e internacional, transformando-o num direito universal da humanidade. Somente sob essa condição podemos nos orgulhar de estarmos avançando continuamente no sentido de uma paz perpétua ${ }^{1}$.

Essa visão otimista de "uma sociedade civil que pode administrar a justiça universalmente" 2 em escala mundial é negada pelo fato de a maior e mais influente potência mundial de hoje — os Estados Unidos - ter rejeitado essa relativização cosmopolita de sua soberania. Entre os muitos motivos para essa recusa não é dos menores o temor de que a perda do poder de decidir por si mesmo quanto à aplicação de força ameaçaria também a segurança de seu modo de vida livre, que pode parecer a realização da idéia kantiana. Os ataques terroristas de 11 de setembro de 2001 e o terrorismo internacional atual parecem confirmar essa apreensão quase que diariamente. Suspeita-se que os verdadeiros inimigos do cidadão cosmopolita não são os Estados assassinos, mas terroristas e suas redes internacionais, líderes militares, governos criminosos ("Estados párias") e o crime organizado. Diante dessas ameaças, os cidadãos mundiais voltam a se refugiar no estatuto de cidadão nacional a fim de obrigar o Estado a tomar medidas apropriadas para protegê-los. As ordens jurídicas nacionais do Ocidente estão no meio do caminho entre a disciplina constitucional do direito penal e do poder de polícia e um direito da segurança transnacional, instituído para além das constituições nacionais. Tais ordens jurídicas jáhaviam começadoessa transição antes da crescenteameaça terrorista da qual o 11 de setembro é o marco principal. Esse crime serviu apenas para acelerar - embora com muita intensidade - o desenvolvimento de uma arquitetura transnacional de segurança, processo que já estava em andamento.Essa arquitetura intervém profundamente nas liberdades civis individuais, tanto nos direitos básicos dos cidadãos dos Estados como nos direitos humanos dos cidadãos mundiais (world citizens). A liberdade garantida ao cidadão tomado como cidadão do mundo parece ser suprimida pelas regras que tratam da segurança. Um exemplo vindo da União Européia (UE) esclarece essa dialética de ganhos e perdas de liberdade. Após a abertura das fronteiras estabelecida pelo Acordo de Schengen, os controles que eram feitos originalmente na fronteira foram transferidos para dentro do país. Alguns estados alemães introduziram a assim chamada Schleierfahndung [investigação velada], que permite abordar pessoas, independentemente de qualquer suspeita, dentro do marco do "combate preventivo à criminalidade". Ou seja,
[1] Kant, I. "Perpetual peace: a philosophical sketch". In: Reiss, Hans (ed.). Kant: political writings. $2^{\mathrm{a}} \mathrm{ed}$. Cambridge: Cambridge University Press, 1991, pp. 107-108.

[2] Idem. "Idea for a universal history with a cosmopolitan purpose", op.cit., p. 45, quinta proposição. 
a expansão da liberdade de movimento através das fronteiras (sem controle na travessia) foi acompanhada de uma perda de liberdade no interior do Estado (maior controle interno antes mesmo de se concretizar a situação limite em que se configuraria a suspeita de um perigo ou crime). A seguir, delinearei essa arquitetura transnacional de segurança e mostrarei como ela dissolve as categorias jurídicas tradicionais que preservam a liberdade. Em uma terceira etapa, procurarei os motivos e as explicações que atualmente legitimam, e por meio dos quais se aceita amplamente, a prioridade da segurança sobre a liberdade.

\section{A ARQUITETURA TRANSNACIONAL DE SEGURANÇA}

Ao lado do direito penal, as regras que disciplinam o poder de polícia são elementos constituintes básicos da arquitetura da segurança, entre os quais se incluem medidas de inteligência e operações militares. Juntos, constituem equivalentes funcionais para a criação de um "espaço de segurança interna", cujos limites externos não coincidem mais com as fronteiras nacionais, mas abrangem todos os Estados que buscam conjuntamente o objetivo de fornecer segurança. A União Européia compromete-se, assim, numa redundância notável do Artigo 29 da proposta de Constituição da UE, a "oferecer aos cidadãos um alto grau de segurança dentro de um espaço de liberdade, segurança e justiça, mediante o desenvolvimento de um procedimento comum dos Estados membros no campo da polícia e da cooperação judicial em assuntos penais [...]". Desse modo, o direito penal já está alinhado com a provisão de segurança. Isso é confirmado pelo Projeto de Tratado que estabelece uma Constituição para a Europa (Art. III-158), que obriga a UE a coordenar a cooperação de forças policiais e órgãos de direito penal a fim de "garantir um alto grau de segurança". O "espaço de liberdade, segurança e justiça” é um dos objetivos da União (Art. III). Na Carta dos Direitos Fundamentais, liberdade e segurança são nomeadas ao mesmo tempo; o Artigo II-6 diz: "Toda pessoa tem o direito à liberdade è̀ segurança".

A escolha de meios para criar o espaço de segurança não se rege por princípios e por suas condições de aplicação, mas pelo objetivo de estabelecer um alto grau de segurança e pelas condições limitantes dos respectivos perigos e oportunidades. Os perigos contra os quais a arquitetura transnacional de segurança está sendo erguida são o crime organizado e, como o 11 de setembro de 2001 intensificou e acelerou um processo já iniciado, o terrorismo internacional. Desde então, quase que só se fala de direito penal em conexão com a segurança interna, e cada reforma do direito penal está baseada num pacote de medidas que inclui, além das regras sobre poder de polícia, os serviços secretos e, agora, também as forças militares. Isso 
ampliou ainda mais os limites e os poderes em cada área do direito. No que diz respeito ao poder de polícia, cujas regras possibilitam medidas proporcionais de defesa contra perigos concretos, o limiar foi movido para muito além da suspeita da existência de uma situação de perigo: a possibilidade de ação da autoridade depende apenas de uma avaliação subjetiva. Começou há muito tempo o processo de expansão do direito penal a tal ponto que ele passa a violar os interesses protegidos por lei. Além disso, a luta contra o crime organizado abriu as portas para um enrijecimento drástico do direito penal material e processual (Lei de Controle do Crime Organizado, 1992). Ao mesmo tempo, isso levou a uma setorialização do processo penal: quando se investiga o crime organizado, permite-se mais e pode-se intervir nos direitos básicos de forma mais profunda e abrangente do que em outros casos. A atenção pública estava voltada para a introdução dos chamados Grossen Lauschangriffs - grampos em residências privadas - tanto nas regras que disciplinam o poder de polícia no nível dos estados como no processo penal. A eqüidade dos procedimentos diminui proporcionalmente ao grau de organização dos criminosos perseguidos. Ademais, medidas preventivas contra ameaças e repressão policial estão cada vez mais entrelaçadas; a possibilidade de intercâmbio entre elas que já se vislumbra no horizonte está firmemente ancorada: provas obtidas no combate preventivo ao crime também podem ser usadas nos procedimentos preliminares, e isso muito antes da configuração de uma suspeita inicial. Por fim, romperam-se as fronteiras não somente entre prevenção do perigo e autoridades de investigação criminal, mas também entre estas e os serviços de inteligência: o Serviço Federal de Inteligência alemão pode iniciar processos criminais baseados em suas descobertas (Art. I § 1-3 Gio)3. Isso é um sinal de que a luta contra o crime organizado também tem sido levada a cabo, há muito tempo, com a utilização de meios militares e de serviços de inteligência. A descrição outrora crítica dessa transformação como "direito penal do inimigo" [Feindstrafrecht] adquiriu um sentido positivo4. Por fim, a ficção de um direito penal unificado e, em especial, de um procedimento penal unificado, deveria também ser abandonada. $\mathrm{Na}$ verdade, há muito tempo existem procedimentos completamente diferentes no direito penal que, por sua vez, são apenas tijolos da construção de uma arquitetura transnacional de segurança.

Podemos falar de transnacionalização pois muitos Estados, juntos e de forma coordenada, estão reformando suas ordens jurídicas nacionais respectivas na mesma direção. Isso não se manifesta tanto num fundamento jurídico comum de vigência transnacional ou no estabelecimento de uma autoridade de segurança onipotente, mas sim na forma de coordenação e cooperação intergovernamentais. Os governos
[3] Ver a apresentação resumida de Albrecht, Peter-Alexis. Die vergessene Freiheit. Berlim: BMW, 2003, p. 96.

[4] Sobre o desenvolvimento de um "direito penal para o inimigo" orientado para categorias militares e preocupado com (supostas) ameaças globais representadas pela criminalidade, ver Jakobs, Günther. "Das Selbstverständnis der Strafrechtswissenschaft vor den Herausforderungen der Gegenwart". In: Eser, A., Hassemer, W. e Burkhardt, B. (eds.). Die deutsche Strafrechtswissenschaft vor der Jahrtausendwende. Munique, C. H. Beck, 200o, pp. 46ss. 
concordam em tomar os mesmos tipos de medidas preventivas e repressivas de combate ao crime, de tal forma que a soberania legislativa nacional permanece intocada. Os resultados, no entanto, encaixam-se de tal modo que surge funcionalmente um direito de segurança transnacional homogêneo. Além disso, surgem redes intergovernamentais por meio da cooperação transnacional iniciada pelos governos entre os serviços de inteligência e as autoridades policiais e de persecução penal, sobretudo no que diz respeito ao intercâmbio de informações. Essas redes são compostas por diferentes autoridades estatais, tanto em nível nacional, numa interconexão entre polícia, justiça penal, serviço secreto e autoridades militares, como em nível transnacional, numa rede que atravessa as fronteiras nacionais.

Esse desdobramento não contradiz o já citado declínio da significação da soberania nacional por meio da relativização dos direitos humanos? O conceito moderno de soberania pressupõe não somente um monopólio das tomadas de decisão finais e mais importantes, mas também dos meios de força. Porém, o monopólio militar e policial da força, paralelo ao monopólio da execução e do cumprimento da pena, está cada vez mais separado de sua âncora no terreno místico da soberania nacional e sujeito, por assim dizer, à racionalização técnica da segurança. A função da segurança pode ser desvinculada do Estadonação territorial: que eles ainda coincidam parece ser um fenômeno transitório. Sob esse aspecto, o Estado está se transformando numa agência de segurança que compete e coopera com outros provedores de serviços de segurança. Entre esses, encontram-se os serviços privados, cada vez mais organizados em nível transnacional, bem como as redes e as cooperações intergovernamentais, que também desempenham cada vez mais a função única de oferecer segurança. As agências de segurança estatais não assumem tarefas qualitativamente diversas das assumidas pelos serviços privados. Tais tarefas são apenas quantitativamente maiores e mais complexas. Do mesmo modo, os Estadosnação privatizam cada vez mais as tarefas de segurança, em especial as ações de prevenção de perigo. Esse é também o caso da provisão de segurança externa, como mostra a contratação de serviços privados de segurança pelo governo norte-americano no Iraque. Sempre que o Estado não pode ou não quer mais oferecer segurança, aumenta a demanda por serviços privados nessa área.

Evidentemente, uma conseqüência da organização e comercialização da segurança em termos de mercado é que ela cai sob os imperativos do sistema econômico. A segurança está se tornando um bem escasso e caro pelo qual somente alguns podem pagar, e é distribuída de modo desigual.Afinal, a provisão de segurança pelo Estado ainda se distinguia pelo imperativo do tratamento igual — mesmo que, na realidade, possa ter havido maior ou menor seletividade quanto a quem 
era protegido de quais perigos. Porém, o que é decisivo é que o Estado, no seu papel de agência de segurança, atende a uma demanda por segurança do mesmo modo que os serviços privados o fazem, com a única diferença de que ele não obtém uma recompensa monetária, mas política. Aqueles que exigem segurança de forma política e são fortes o suficiente para recompensar sua provisão de forma também política - por exemplo, com uma maioria de votos na eleição seguinte recebem um "pacote de segurança" correspondente. Do ponto de vista formal, o direito sobre a segurança pode ainda estar preso à legislação nacional e a um poder executivo sujeito à lei, mas, do ponto de vista material, há muito tempo já se separou deles, tornando-se um serviço que pode ser fornecido por quase qualquer um. A provisão de segurança pelo Estado em competição e cooperação com os serviços privados, bem como numa rede transnacional com outros Estados, difere fundamentalmente de uma concepção hobbesiana, em que a provisão de segurança é praticamente a raison d'être da soberania estatal.

\section{A DISSOLUÇÃO DAS CATEGORIAS JURÍDICAS}

Na discussão sobre o equilíbrio apropriado entre liberdade e segurança que ocorreu após 11 de setembro de 2001, a segurança claramente ganhou prioridades. As conseqüências para a política contra o crime fortaleceram o caminho que já havia sido aberto para o surgimento de um direito transnacional de segurança. À arquitetura da segurança foram acrescentados a guerra ofensiva preventiva e o uso da força militar em primeiro lugar - além do caso até então familiar da intervenção humanitária. A rede funcional de direito penal e autoridades policiais, bem como serviços secretos, foi expandida para incluir as forças militares. A guerra no Afeganistão pôde ser justificada de várias formas: como um ato retaliatório de punição, como uma operação de perseguição penal contra aqueles que estavam por trás dos assassinos do 11 de setembro, como uma medida policial preventiva na luta contra o terrorismo internacional e, portanto, para prevenir ataques futuros, ou, ainda, como uma guerra preventiva para se defender de perigos iminentes. Essas diferentes justificativas - independentemente de seu poder de persuasão, altamente questionável ${ }^{6}$ - neutralizam-se umas às outras no que diz respeito a seus pressupostos e conseqüências jurídicas. As categorias jurídicas dissolvem-see, com elas, as competências e as responsabilidades, os deveres e a accountability por sua possível violação, bem como o modo como o exercício da autorização legal pode ser judicialmente supervisionado. Uma ação policial está ligada às precondições impostas pelas regras sobre poder de polícia a existência de um perigo e a proporcionalidade do ataque - por meio da revisão de um tribunal administrativo; uma medida de perseguição
[5] Para uma crítica dessa falsa oposição no que diz respeito ao debate nos Estados Unidos, ver Dworkin, Ronald. "The threat of patriotism". New York Review of Books, vol. XLIX, $\mathrm{n}^{\mathrm{O}} 3,28 \mathrm{fev}$. 2002,pp. 44-49, esp.p. 48.

[6] Para uma visão crítica a esse respeito, ver Prittwitz, Cornelius. "Krieg als Strafe: Strafe als Krieg". In: Prittwitz, C. e outros [eds.]. Festschrift für Klaus Lüderssen. Baden-Baden: Namos, 2002, pp. 499-514. 
[7] Sobre essa questão, ver Fletcher, George P. Romantics at war: glory and guilt in the age of terrorism. Princeton: Princeton University Press, 2002.

[8] Bush, George W. "The national security strategy of the United States", 17 de setembro de $2002<$ http://www.whitehouse.gov/nsc/ nss. html , acessado em 12/11/2008. Sobre a subjetivização das precondições da ação policial, ver Poscher, Ralf. Gefahrenabwehr: Eine dogmatische Rekonstruktion. Berlim: Duncker \& Humblot, 1999 . penal está ligada à apresentação de fundamento para suspeita e está, do mesmo modo, sujeita ao princípio restritivo da proporcionalidade, com as revisões judiciais correspondentes; um ato de punição não pode acontecer sem um processo justo e reações previamente estabelecidas, e a pena em si deve ser proporcional e, sobretudo, deve atingir somente os culpados e não os inocentes, com os assim chamados "danos colaterais". Uma guerra de defesa preventiva poderia mover-se dentro de uns poucos marcos jurídicos muito bem definidos; porém, o direito humanitário internacional já proibiu várias medidas militares, em especial no que diz respeito ao tratamento de prisioneiros e à interação com a população civil.

A dissolução dos limites legais torna-se clara no tratamento dos prisioneiros em Guantánamo. O estatuto deles nãoestá de forma alguma claro, sua designação muda de presos comuns para prisioneiros de guerra ou detidos preventivos segundo a justificação necessária a cada momento e as críticas que se pretenda rechaçar. Com a invenção do estatuto de "combatente ilegal", o governo dos Estados Unidos parece querer evitar todas as designações costumeiras, junto com os direitos que lhes estão associados7. A captura de Saddam Hussein pelos militares norte-americanos foi anunciada ao público com o comentário "Nós o pegamos!" - como acontece quando as autoridades policiais anunciam a captura de um suposto delinqüente. Dessa perspectiva, a guerra do Iraque teria sido uma enorme operação para efetivar as leis. Por sua vez, outra coisa é a nova doutrina da guerra ofensiva preventiva. Para ela, os argumentos apresentados são semelhantes aos de medidas policiais contra o perigo, com a mesma tendência a aumentare tornar subjetiva a possibilidade de avaliar a existência de uma situação em que se configura um limiar de suspeita suficiente para justificar a ação - como quando a polícia determina a iminência de uma ameaça de acordo com suas próprias estimativas. Como diz a doutrina Bush sobre o uso preventivo da força: "Quanto maior a ameaça, maior é o risco da inação - e mais convincente o argumento a favor de ações antecipatórias para nos defender, mesmo quando há incerteza quanto ao momento e o lugar do ataque inimigo" ${ }^{8}$. Essa doutrina pode ser lida, ao mesmo tempo, como a declaração central do novo direito de segurança transnacional.

Ademais, na forma de coordenação intergovernamental, promulgaram-se novas leis de segurança em várias séries, reunindo e atualizando os desdobramentos descritos acima. Pode-se mostrar isso de forma exemplar nos dois "pacotes de segurança" alemães, cujas provisões individuais foram decididas nos dois últimos anos. Fortaleceu-se a integração estreita entre direito penal e poder Executivo com a introdução do parágrafo 129b no Código Penal, que amplia a criminalização das condutas daqueles que fornecem apoio a uma organização terrorista 
no exterior, mas, ao mesmo tempo, submete sua perseguição à autoridade do poder Executivo (o ministro da Justiça Federal), e isso sob uma precondição tão vaga quanto o menosprezo pela "idéia de compreensão internacional". Mas, sobretudo, expandem-se os poderes de controle e coleta de informações das autoridades. Isso foi enfrentado apenas com argumentos organizacionais práticos em defesa de uma divisão institucional entre forças militares, serviço secreto, polícia e autoridades encarregadas da persecução penal. Erhard Denninger já fala, nesse contexto, de uma "associação funcional de investigação preventiva entre os serviços de inteligência e a polícia no campo da luta contra o terrorismo" 9 . Com efeito, para a agência de segurança estatal, o monopólio dos meios de violência é ainda essencial; porém, o objetivo do combate preventivo ao terrorismo se transfere para antes da suspeita de perigo, sobretudo por meio da coleta, do armazenamento e da transferência abrangentes de informação. Portanto, a associação funcional de investigação preventiva consiste, sobretudo, na regulação organizacional e legal dos poderes de coleta de dados atribuídos às diferentes autoridades de segurança, ordem pública, perseguição penal e inteligência, bem como nos fluxos desimpedidos de dados entre elas ${ }^{10}$. Desse modo, ocorre uma intervenção profunda nas liberdades civis básicas dos cidadãos, em especial no direito de autodeterminação relativa à informação. As proteções legais determinadas pela constituição contra a invasão dos direitos básicos fracassaram na maioria dos casos porque, graças ao sigilo necessário das medidas, os tribunais não sabem nada a respeito delas, de tal modo que até a supervisão judicial para garantir a liberdade permanece, em larga medida, excluída.Isso também limita a liberdade dos cidadãos. Por fim, a função de proteção da liberdade da divisão de poderes também corre perigo quando as autoridades que estão deliberadamente situadas em diferentes níveis do governo (por exemplo, o serviço de inteligência federal, as autoridades policiais e de persecução penal estaduais) se combinam por meio de uma rede de informação, e o serviço de inteligência adquire poderes investigativos. A separação de funções e autoridades da prevenção de ameaças, de persecução penal, bem como de inteligência e reconhecimento militar está entre os princípios básicos de uma divisão de poderes que garante a liberdade.É somente a estrutura em rede das diferentes agências, atribuídas a diferentes autoridades, que distingue uma associação funcional de investigação de um órgão de segurança centralizado.

\section{POR QUE SE ANTEPÕE A SEGURANÇA À LIBERDADE?}

Embora a lei de segurança transnacional nascente, promulgada ainda em grande parte por meio de legislação nacional, atinja profundamente os direitos básicos e humanos, e que as proteções legais
[9] Denninger, Erhard. "Freiheit durch Sicherheit? Anmerkungen zum Terrorismusbekämpfungsgesetz". Strafverteidiger, 2002, p. 99.

[10] Para detalhes a esse respeito, ver Lepsius, Oliver. "Freiheit, Sicherheit, Terror". Leviathan, 2004, pp. 74ss. 
[11] A esse respeito, ver Albrecht, op.cit.

[12] Ignatieff, Michael. The lesser evil: political ethics in an age of terror. Princeton/Oxford: Princeton University Press, 2004, p. 59

[13] Ibidem, pp. 59 e 61 . contra as infrações dos direitos cometidas pelo Estado estejam encolhendo e fiquem expostas ao poder invasor cumulativo de uma rede de segurança transnacional com base nos Estados, os cidadãos não percebem isso como uma restrição de seus direitos, ou então aceitam tal restrição sem resistência. É difícil não suspeitar que a ameaça encenada pelos meios de comunicação de massa os convertem em vítimas de temores irracionais que são depois explorados por políticos populistas para seus propósitos, ou que simplesmente "esqueceram" de seus direitos civis ${ }^{11}$.

Michael Ignatieff adverte, no entanto, contra a suposição de que a maioria que apóia ou aceita as restrições aos direitos civis básicos é simplesmente estúpida ou negligente: "A não ser que assumamos que as pessoas são ingênuas, precisamos considerar a possibilidade de que medidas fortes, danosas para as liberdades civis, na verdade agradam a opinião da maioria" ${ }^{12}$. A aceitação das restrições às liberdades talvez se explique, por outro lado, pelo fato de essa lei de segurança funcionar, na luta mundial contra o crime organizado e o terrorismo internacional, como uma promessa de segurança aos "bons" cidadãos. As pessoas talvez estejam dispostas a aceitar restrições às liberdades porque lhes dão razões para esperar que, na qualidade de "bons" cidadãos, elas não venham a ser de forma alguma afetadas. "É improvável que a maioria dos cidadãos venha a suportar quaisquer dos custos diretos do cerceamento"13. Em termos de custobenefício, as pessoas estão provavelmente dispostas a aceitar um grau maior de restrições potenciais à liberdade se o alcance real de sua liberdade como um todo é aumentado ou estabilizado - supondose que as restrições potenciais à liberdade sejam reais apenas para a minoria de "ovelhas negras", não para a maioria que se beneficiará de fato com a expansão e a segurança do espaço de liberdade. Isso é ainda mais válido quando se trata da liberdade econômica, pois as restrições impostas pela lei de segurança afetam somente os direitos civis burgueses clássicos.

Tudo isso significa, evidentemente, a anulação do contrato social. Esse tipo de legislação viola uma norma fundamental que está na base da distinção entre maioria e minoria no processo de legislação democrática. Kant referia-se a essa norma fundamental como sendo uma característica definidora de uma constituição republicana. É a norma da imparcialidade ou reciprocidade da legislação que garante a liberdade e a igualdade dos cidadãos. De acordo com Kant, a liberdade externa e legítima é "uma autorização para não obedecer a leis externas, exceto aquelas às quais eu possa dar meu consentimento", ao passo que a igualdade dentro de um Estado é "aquela relação entre os cidadãos pela qual ninguém pode pôr outra pessoa sob uma obrigação legal sem se submeter simultaneamente a uma lei que exija que ele mesmo 
seja posto sob o mesmo tipo de obrigação pela outra pessoa"14. Essa regra fundamental não funciona mais se posso prever que uma lei que restringe a liberdade não afetará a mim, mas a outra pessoa. Isso é inteiramente possível sob o manto de uma lei geral que se aplica a um número indeterminado de casos e pessoas, isto é, a todos os cidadãos igualmente. A universalidade semântica da lei não pode evitar sua aplicação seletiva e discriminatória. Quando uma lei que permite ao Estado grampear apartamentos privados afeta apenas uma minoria, ou quando uma lei submete estrangeiros a uma vigilância especial, então a maioria pode prever que não será afetada, que ninguém pode reciprocamente submetê-la à mesma lei.A lei geral torna-se então um instrumento de dominação de uma maioria sobre uma minoria.

Ora, nem Kant nem os outros filósofos da tradição republicana, de Rousseau a Rawls, afirmaram alguma vez que esse teste de imparcialidade tinha de funcionar na realidade. A hipotética autoaplicação de uma lei restritiva da liberdadé é suficiente para testar se ela permite ou não privilégios ou discriminações ilegítimas. Porém, essa auto-aplicação hipotética sempre fracassa quando posso ver por trás do véu da ignorância e saber que uma lei, embora formal, não pode realmente me afetar. Em seu famoso e contestado ensaio de 1937 sobre "A transformação funcional do direito na sociedade burguesa", Franz Neumann conjecturou que a característica essencial do capitalismo monopolista era a instrumentalização da generalidade do direito em favor de interesses particulares ${ }^{15}$. Hoje, parece que a maioria está instrumentalizando a lei geral a fim de defender sua forma de vida contra a das minorias. O que está surgindo é uma eticização da lei geral pela qual a maioria protege seu entendimento das liberdades civis, seu modo de vida livre. Esseentendimento é seletivo: ele valoriza determinados aspectos da liberdade mais do que outros. Somente as violações de alguns aspectos da liberdade - e não de outros - são consideradas ilegítimas.

Um exemplo simples deixa claro quais aspectos da liberdade estão envolvidos: hoje, um aumento de imposto é percebido como um ataque mais grave à liberdade do que o grampeamento de residências privadas ou as restrições relacionadas com as leis contra o terrorismo discutidas acima. A transformação do Estado, confirmada na área dos direitos humanos, de seu papel original de fiadoreoponente nato dos direitos humanos para o de protetor deles contra terceiros pode ser registrada também nas regras sobre poder de polícia e direito penal doméstico. O Estado que pune e defende contra ameaças não é percebido, em geral, como um destruidor potencial da liberdade, mas como um protetor que sempre faz pouco. As ameaças à liberdade vindas de terceiros são levadas mais a sério do que aquelas legadas por uma longa experiência histórica, advindas de intrusões arbitrárias do Estado.
[14] Kant, "Perpetual peace", op. cit., p.99, primeiro artigo definitivo.

[15] Neumann, Franz. "Der Funktionswandel des Gesetzes im Recht der bürgerlichen Gesellschaft". Demokratischer und autoritärer Staat, $\mathrm{n}^{\mathrm{O}}$ $63,1967, \mathrm{pp} \cdot 7-57$. 
[16] Para uma visão geral detalhada, ver Grimm, Dieter. Recht und Staat der bürgerlichen Gesellschaft. Frankfurt: Suhrkamp, 1987; Böckenförde, Ernst-Wolfgang. Staat, Gesellschaft, Freiheit. Frankfurt: Suhrkamp, 1976.

[17] Uma ênfase na oposição à concepção antiga de liberdade encontra-se em Constant, Benjamin. "De la liberté des anciens compareés à celle des modernes". In: De l'esprit de conquête et de l'usurpation. Paris: Flammarion, 1986 [1819], pp. 26591. Não obstante, Quentin Skinner mostra que essa visão antiga desempenhou um papel central na autoconstituição da sociedade civil republicana moderna (Liberty before liberalism. Cambridge: Cambridge University Press, 1998).

[18] Ver o resumo preciso de Rudolf Wiethölter em "Bürgerliches Recht". In: Görlitz, Axel (ed.). Handlexikon zur Rechtswissenschaft. Reinbek b. Hamburg, 1974, vol. 1, pp. 47-54.
A seguir, gostaria de reconstituir essa transformação com o exemplo de seus efeitos sobre o direito penal que, até o momento presente, sempre foi compreendido como algo que possibilita e protege a liberdade.

A consciência moderna da liberdade desenvolveu-se inicialmente na história por experiências negativas com o Estado que, em decorrência de sua natureza (a posse do monopólio da violência e o interesse dominante na autopreservação), busca restringir a liberdade individual. $\mathrm{Na}$ origem, foram especialmente as violações da liberdade de religião que aguçaram a consciência da liberdade; depois, vieram para o primeiro plano as arbitrariedades do Estado absolutista (prisões arbitrárias, lettres de cachet) e a regulamentação estatal da economia até os menores detalhes (mercantilismo, a luta por liberdade econômica). Aqui também a libertação dos laços de um Estado do bem-estar paternalista era ao mesmo tempo percebida como uma ameaça (resistência das guildas). Por fim, no século XIX, surgiram as restrições à liberdade de opinião, de imprensa e de reunião. Esses poucos e certamente não exaustivos estágios do desenvolvimento histórico da consciência moderna da liberdade deixam suficientemente claro que a semântica da liberdade se alimentou principalmente do conflito com o Estado ${ }^{16}$. Fenomenologicamente, a liberdade moderna é uma questão de liberdade conquistada contra o Estado ${ }^{17}$. Essas experiências históricas podem explicar por que a inversão de papel dos cidadãos que criaram o direito penal, de autores a destinatários da legislação, foi, ao menos parcialmente, bem-sucedida. Até mesmo um "bom" cidadão podia ter experiências negativas com o Estado punitivo porque pertencia a uma associação que fora banida ou expressava opiniões que, tachadas de traidoras, eram perseguidas.

A concepção de liberdade do liberalismo evoluiu a partir dessa disputa com e contra o Estado. Uma sociedade autônoma que se regula por si mesma, primordialmente por meio do mercado e da competição, precisa do Estado apenas para garantir a estrutura de auto-regulação - liberdade igual mediante leis gerais (sobretudo, liberdade de propriedade e de contrato) e segurança externa ${ }^{18}$. Evidentemente, a história das sociedades industriais modernas baseadas nessa concepção de liberdade logo revela suas deficiências: o uso individual da liberdade produz riscos novos que só podem ser absorvidos pela sociedade como um todo. Isso vale especialmente para as conseqüências sociais da ação econômica-racional livre. Os espaços de liberdade individual são, com efeito, formalmente distribuídos de modo igual, mas pressupõe-se o acesso aos recursos materiais para que se possa fazer uso deles de fato. Esse acesso, por sua vez, é distribuído de forma desigual. Ademais, a liberdade individual é ameaçada por perigos que não podem ser controlados pelo indivíduo: acidentes, doenças, desemprego, 
idade. Em reação a essas ameaças, que se transformaram em fontes de instabilidade social, o Estado tornou-se intervencionista, estabelecendo a igualdade social mediante a redistribuição, de tal modo que a liberdade individual pudesse ser exercida igualmente não só de forma normativa, mas também de fato ${ }^{19}$. Com o objetivo de controlar recursos suficientes para redistribuição, o próprio Estado tornou-se mais tarde economicamente ativo, assumindo o comando econômico: investimentos, subsídios, empresas e bancos estatais. Quando os gastos públicos, como porcentagem do PIB, aumentaram, a separação entre o Estado e a sociedade (essencialmente auto-reguladora) tornou-se obsoleta. Desse modo, o Estado passa de adversário da liberdade a seu fiador.Isso transforma a experiência geral da liberdadee molda concretamente como ela écompreendida:de liberdade pela qual lutamos para nós mesmos, protegida pelo Estado apenas em seus limites externos por leis determinadas, abstratas, gerais, previsíveis, ela passa a ser uma liberdade constituída pelo Estado. A segurança social torna-se então rapidamente uma segurança abrangente em face de todos os riscos e perigos, contra os quais se esperam garantias oferecidas pelo Estado intervencionista ${ }^{20}$. No paradigma do Estado do bem-estar social, a criminalidade é, da mesma forma, interpretada como essencialmente um problema social ao qual o Estado intervencionista reage com meios específicos: "a criminalidade era um problema social [...] apresentado na forma de atos criminosos individuais" ${ }^{21}$. Conseqüentemente, a criminalidade tem suas causas explicadas por circunstâncias psíquicas e sociais que fizeram do delinqüente o que ele era no momento do crime. Acima de tudo, a desigualdade social, com suas conseqüências de privação, marginalização e discriminação, é considerada o fator causal mais importante para explicar o comportamento desviante:

Se havia uma explicação central, era a assistencialista da "privação social" e, posteriormente, a da "privação relativa". Os indivíduos tornavam-se delinqüentes porque eram privados de educação adequada, ou de socialização familiar, ou de oportunidades de emprego, ou de tratamento adequado para seus problemas sociais e psicológicos ${ }^{22}$.

Em conseqüência, a reação à criminalidade não deveria proteger a sociedade apenas: deveria compensar a socialização inadequada.

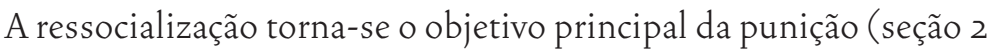
do Código Penal alemão). Também nessa perspectiva a inversão de papel entre os cidadãos que redigem a lei penal e seus destinatários ainda é possível. O criminoso pertence inerentemente à sociedade; por causa da desvantagem e da privação social (em relação à qual o indivíduo pouco ou nada pode fazer, mas a sociedade pode fazer tudo ou bastante), ele se tornou um delinqüente. Portanto, é impe-
[19] Para um resumo, ver Stolleis, Michael.Konstitution und Intervention. Frankfurt: Suhrkamp, 2001.

[20]Isensee, Josef. Das Grundrecht auf Sicherheit. Berlim/Nova York: Walter de Gruyter, 1983.

[21] Garland, David e Sparks, Richard (eds.). Criminology and social theory. Oxford/Nova York: Oxford University Press, 200o, p. 8.

[22] Ibidem, p. 9. 
[23] A esse respeito, ver Honneth, Axel (ed.). Befreiung aus der Mündigkeit: Paradoxien des gegenwärtigen Kapitalismus. Frankfurt/Nova York: Campus, 2002.

[24] Bobbitt, Philip. The shield of Achilles. Londres: Penguin, 2003.

[25] Ibidem, p. 229.

[26] Ibidem. rativo que se tomem medidas apropriadas para transformá-lo num membro livre e igual da sociedade, para ajudá-lo a levar uma vida isenta de punição e fazer uso de sua liberdade de uma maneira que não cause dano aos outros.

Não foram somente os déficits na implementação desse programa que levaram ao abandono da ressocialização e de todo o paradigma do Estado do bem-estar. A crise fiscal do Estado gerencial, a globalização da economia com suas diversas conseqüências, as revoluções na tecnologia das comunicações - tudo isso contribuiu para uma mudança de amplo alcance no pensamento sobre o Estado e sua relação com a sociedade ${ }^{23}$. O Estado do bem-estar era nacional e se as múltiplas reivindicações de que era alvo podiam ser satisfeitas, isso acontecia somente no interior do território traçado pelas fronteiras nacionais. $\mathrm{O}$ Estado de hoje, ao contrário, é um "Estado-mercado", na expressão de Philip Bobbitt ${ }^{24}$, que age transnacionalmente, sobretudo para globalizar o sistema econômico a fim de assegurar oportunidades melhores para seus eleitores:

Esse tipo de Estado depende dos mercados de capitais internacionaise, em menor grau, da moderna rede de empresas multinacionais para criarestabilidade naeconomia mundial, em preferência à gestão porórgãospolíticos nacionais ou transnacionais 25 .

Enquanto o Estado do bem-estar busca promover um bem comum nacional redistribuindo ou fornecendo ele mesmo bens, para o Estadomercado trata-se de expandir e assegurar opções e oportunidades:

Tal como para o Estado-nação, para ele o Estado não passa de um provedor minimo ou redistribuidor. Enquanto o Estado-nação se justificava como um instrumento para servirao bem-estar do povo (a nação), o Estado-mercado existe para maximizaras oportunidades gozadas portodos os membros da sociedade ${ }^{26}$.

Essa mudança de perspectiva criou uma compreensão negativa da liberdade, contra o modelo anterior do Estado do bem-estar, da condição de possibilidade da liberdade individual organizada pelo Estado e construída por meio da ação solidária. O Estado de bem-estar e suas normas jurídicas são agora vistos como restrições ilegítimas à liberdade - "ilegítimas" porque a liberdade consiste primeiramente na liberdade individual de escolha. A liberdade é essencialmente liberdade para consumir. O Estado não deve redistribuir os recursos diretamente para alguns e, desse modo, restringir a liberdade de outros, mas expandir as escolhas individuais e aumentaro espaço das opções. Desse ponto de vista, as normas jurídicas do Estado do bem-estar fun- 
cionam como um equivalente dos impostos, com os mesmo efeitos negativos: elas restringem as escolhas possíveis dos consumidores ao tomar seus recursos financeiros e usá-los para o bem comum, e, em relação a isso, o indivíduo não pode decidir por si mesmo. Além disso, dificultam a orientação para a oferta, essencial para a economia do Estado-mercado. O valor das normas legais é medido pelo fato de aumentarem ou diminuírem os custos de transação. O Estado-mercado, que busca exatamente aumentar as escolhas individuais e diminuir os custos de transação, precisa, portanto, retirar-se das tarefas de promover o bem comum, típicas do Estado do bem-estar. Os meios para isso são a desregulamentação e a privatização.

Enquanto o Estado-mercado se retira do espaço interno da liberdade de consumo e deixa, em larga medida, a competição econômica global entregue a si mesma - uma vez que qualquer regulamentação legal é medida exclusivamente por seu efeito de expandir ou contrair o espaço das opções, de aumentar ou diminuir os custos de transação - , o oposto ocorre nos domínios em que crescem as ameaças a esse espaço interno. Trata-se dos efeitos colaterais disfuncionais descritos acima: movimentos migratórios, crime organizado, mau funcionamento interno do sistema econômico, assim como, mais recentemente, o terrorismo internacional. Além disso, a liberdade consumista, tal como qualquer aumento de liberdade, tem seu lado negro ameaçador: aumento do individualismo, dissolução dos laços sociais e das tradições, risco de fracassar na competição econômica, tornando-se um dos perdedores da modernização e da globalização. É provavelmente a partir da experiência desses riscos que se desenvolve um temor enorme da criminalidade, que reúne os medos de uma sociedade de múltiplas opções. O outro, com sua multiplicidade de opções altamente individualizada, torna-se um risco para a segurança. É nesse ponto que entra o Estado da segurança. As reformas econômicas promovidas nos Estados Unidos por Ronald Reagan e na Grã-Bretanha por Margaret Thatcher foram acompanhadas por um forte aperto do direito penal e criminal. A liberação da economia em relação ao Estado baseava-se numa simultânea restrição aos direitos civis tradicionais, o que, não obstante, era afirmado como "liberdade através do Estado" - a saber, como proteção da liberdade consumista das ameaças de terceiros. Esses terceiros estão situados fora do espaço interno desregulado e, portanto, estão excluídos de qualquer modo, ou excluídos devido à falta de sucesso em vender sua força de trabalho no mercado. Da perspectiva interna do espaço protegido da sociedade de múltiplas opções, os imigrantes ilegais são, de certo modo, a figura exemplar daquilo contra o qual devemos nos proteger: tal como alguém que pegasse uma carona no "dilema do prisioneiro", essencial para a legitimação do Estadomercado, eles querem ganhar acesso ilegítimo ao espaço de segurança 
[27] Jürgen Habermas observa essa eticização na política hegemônica do governo Bush em Der gespaltene Westen. Frankfurt: Suhrkamp, 2004.

[28] Krisch, Nico. "Amerikanische Hegemonie und liberale Revolution im Völkerrecht". Der Staat, vol. $43, \mathrm{n}^{\circ}$ 2, 2004, p. 33 . e liberdade, para gozar de suas vantagens sem que as restrições à liberdade a isso conectadas sejam experimentadas pela maioria como uma ameaça. Na medida em que gozamos de nossa liberdade consumista dentro do espaço interno da sociedade de opções múltiplas, não podemos conceber cair no espaço da exclusão social, onde as restrições formais e gerais à liberdade têm efeitos concretos e materiais. $\mathrm{O}$ Estado de segurança é o outro lado da moeda do Estado-mercado, do direito de segurança transnacional, o outro lado da sociedade desregulada, global, de múltiplas opções.

Não é difícil transferir essa mudança interna no entendimento da liberdade para o nível internacional. A concepção de liberdade atualmente dominante no Ocidente distingue-se pela ligação dos direitos humanos e da democracia à economia de mercado que, entre outras coisas, deve ser implementada globalmente por meio da liberalização do comércio mundial. Os Estados Unidos e a Europa ocidental distinguem-se menos pelo fim do que pelos meios de alcançá-lo. O objetivo da sociedade civil governada universalmente pela lei passou a ser uma sociedade global de múltiplas opções. O perigo é que se declara que o éthos desse modo de vida é a interpretação autêntica da idéia kantiana e ele se torna vinculante no direito internacional ${ }^{27}$. As medidas de segurança transnacionais asseguram a defesa desse modo de vida. Em relação aos outros súditos do direito internacional, isso repete a violação da regra de reciprocidade que já foi observada no direito de segurança nacional. O mundo ocidental influencia a implementação de normas jurídicas internacionais sem, ao mesmo tempo, considerar-se o destinatário delas ${ }^{28}$. A última conferência da $\mathrm{OMC}$ mostrou a resistência que esse mundo apresenta quando se trata, pelo menos uma vez, da auto-aplicação de seus próprios princípios. Uma perspectiva cosmopolita exige transcender a perspectiva interna do modo de vida livre da sociedade de múltiplas opções. O Ocidente ainda precisa dar esse passo.

KLAUS GÜNTHERé professor de Teoria Jurídica e Direito Penal na UniversidadeJ.W.Goethe, Frankfurt. É autor de The sense of appropriateness:application discourses in morality and law (1993) e co-editor de Die Öffentlichkeit der Vernunft und die Vernünft derÖffentlichkeit (2001). 